\title{
Target-dependent Hormonal Control of Neuron Size in the Rat Spinal Nucleus of the Bulbocavernosus
}

\author{
Isao Araki, Yoshio Harada, ${ }^{a}$ and Motoy Kuno \\ Department of Physiology, Kyoto University Faculty of Medicine, Kyoto 606, Japan
}

\begin{abstract}
The spinal nucleus of the bulbocavernosus (SNB) in the rat is a cluster of sexually dimorphic motoneurons that innervate perineal muscles. In adult male rats, the size of SNB neurons is reduced following castration, and this effect is reversed by treatment with testosterone. However, androgen receptors are present in the perineal muscles as well as in SNB neurons. Therefore, it is not clear whether the neuronal size is regulated by direct action of the hormone on SNB neurons or by a target-derived factor that may be controlled via hormonal action on the innervated muscle. To address this question, the peripheral (pudendal) nerve of SNB neurons on one side was cut and united to the grafted soleus muscle, which lacks androgen sensitivity. On the control side, the pudendal nerve was similarly cut but was allowed to reinnervate the perineal muscles. The size of SNB neurons was measured on both sides after a postoperative period of 10 weeks, during which the animal had been castrated or treated with testosterone after castration. The size of SNB neurons that had reinnervated perineal muscles was reduced following castration and enlarged by testosterone treatment. In contrast, the size of SNB neurons that had innervated the soleus muscle remained unaltered in response to testosterone manipulation. It is concluded that hormonal regulation of the size of SNB neurons in adult rats is mediated by their target muscles.
\end{abstract}

The spinal nucleus of the bulbocavernosus (SNB) in the rat is a cluster of lumbar motoneurons localized in the dorsomedial region of the ventral horn and innervates perineal striated muscles, including the bulbocavernosus, levator ani, and external anal sphincter (Breedlove and Arnold, 1980, 1981; Schroder, 1980; McKenna and Nadelhaft, 1986; Ueyama et al., 1987). In adult rats, the number of SNB neurons is three to four times fewer in the female than in the male (Breedlove and Arnold, $1980,1981)$. This sex difference in the number of SNB neurons develops during a critical period at the perinatal stage (Nordeen et al., 1985; Sengelaub and Arnold, 1986, 1989; Sengelaub et al., 1989). Thus, the cell death of SNB neurons during this

\footnotetext{
Received Dec. 28, 1990; revised Apr. 26, 1991; accepted May 2, 1991.

This work was supported by research grants from the Ministry of Education, Science and Culture of Japan and from the Nissan Science Foundation. We thank Dr. Y. Arai for detailed instruction in preparing testosterone capsules and Dr. N. Mizuno for his helpful advice in morphometric measurements of neurons.

Correspondence should be addressed to Motoy Kuno at the above address.

a Present address: Department of Physiology, Nippon Medical School, Tokyo 113, Japan.

Copyright (C) 1991 Society for Neuroscience $0270-6474 / 91 / 113025-09 \$ 05.00 / 0$
}

critical period is predominant in the female, and the magnitude of the cell death in the female can be reduced by treatment with testosterone (Nordeen et al., 1985; Sengelaub and Arnold, 1986).

In adult rats, the number of SNB neurons remains unaltered in response to testosterone manipulation (Arnold, 1984). However, the size or the dendritic length of SNB neurons in adulthood is markedly reduced following castration, and this effect can be reversed by treatment with testosterone (Breedlove and Arnold, 1981; Arnold, 1984; Kurz et al., 1986). After injections of testosterone into adult rats, SNB neurons accumulate the hormone (Breedlove and Arnold, 1980, 1983). Therefore, it is possible that the neuronal size may be regulated by direct action of the hormone on SNB neurons. However, androgen receptors are also present in the perineal muscle (Jung and Baulieu, 1972; Dube et al., 1976). In fact, the perineal muscle in adult rats shows regressive changes following castration, and these changes are prevented by testosterone treatment (Wainman and Shipounoff, 1941; Eisenberg and Gordan, 1950; Venable, 1966). Breedlove (1986) has suggested that the testosterone dependence of the size of SNB neurons may be due to some retrograde trophic influence from the target, which is regulated by the hormone acting on the perineal muscle. This possibility bears similarity to the bchavior of hypoglossal motoneurons (Sumner and Watson, 1971) or sympathetic ganglia (Yawo, 1987; Purves et al., 1988; Snider, 1988; Voyvodic, 1989), in which the dendritic geometry of the neurons is regulated by interactions with their peripheral targets. We have examined whether hormonal regulation of the size of SNB neurons in adult rats may also be mediated by an influence from the target muscle.

\footnotetext{
Materials and Methods

Preparation. Adult, male Wistar rats weighing 180-200 gm were anesthetized by an intraperitoneal injection of sodium pentobarbital $(50 \mathrm{mg} /$ $\mathrm{kg}$ ). SNB neurons innervate perineal muscles through the pudendal nerve. The pudendal nerve was exposed in the ischiorectal fossa for two types of chronic operations. In one type of operation, a branch of the exposed pudendal nerve on the left side was transected just dorsal to the bulbourethral gland. In this region, two pudendal nerve branches can be seen. The dorsal branch supplies the levator ani (also known as the dorsal bulbospongiosus; McKenna and Nadelhaft, 1986; Ueyama et al., 1987), bulbocavernosus (medial and lateral ventral bulbospongiosus), and external anal sphincter, whereas the ventral branch innervates the sphincter urethrae and ischiocavernosus muscles (Ueyama et al., 1987). We cut the dorsal pudendal branch. It is this branch that contains the motor fibers originating from the SNB (also known as the dorsomedial nucleus; McKenna and Nadelhaft, 1986; Ueyama et al., 1987). In preliminary experiments, the cut pudendal nerve branch was found to reinnervate the perineal muscles about 3 weeks after nerve section. Therefore, for the observations on long-term effects of denervation (or axotomy), section of the left pudendal nerve branch was repeated every 2 weeks. In another series of operations, the left soleus
} 
muscle excised from the same animal was immediately placed to the ischiorectal fossa on the left side, and the central stump of the cut dorsal pudendal nerve branch was united to the soleus muscle at its nerve entry zone with 8-0 silk suture (Hanzlikova and Gutmann, 1974). The proximal and distal tendons of the grafted soleus muscle were firmly fixed to the fasciae of the gluteal and tail muscles, respectively, with 6-0 suture so as to maintain approximately its original length in situ under slight tension (Hironaka and Miyata, 1973; Carlson et al., 1979). On the contralateral side, the dorsal pudendal nerve branch was similarly sectioned, but the central and peripheral stumps of the cut nerve were immediately reunited to allow reinnervation of the perineal muscles. In about $10 \%$ of the animals subjected to this operation, the grafted soleus muscle underwent necrosis, the entire muscle mass being replaced with fat tissues. These animals were discarded. For the rest of the operated animals, the grafted soleus muscle could be maintained for a postoperative period of 10 weeks. The wet weight of the grafted soleus muscle was, on average, $71 \pm 20 \%( \pm$ SD) of that of the contralateral, normal soleus muscle observed in seven rats that had received no testosterone manipulation (see below).

Testosterone manipulation. One group of animals was castrated. Also, in another group of animals, testosterone was chronically applied after castration. For this purpose, two Silastic capsules (Dow Corning, 602$285 ; 3.18 \mathrm{~mm}$ o.d., $1.57 \mathrm{~mm}$ i.d., and $45 \mathrm{~mm}$ in length) filled with testosterone powder (Sigma) were subcutaneously implanted in the back (Menniti and Baum, 1981; Matsumoto et al., 1988). The general effect of testosterone inanipulation was roughly evaluated by changes in the wet weight of the bulbocavernosus muscle (see Results).

Morphometric measurements of SNB neurons. After varying postoperative periods, the animal was deeply anesthetized with an intraperitoneal injection of sodium pentobarbital (about $55 \mathrm{mg} / \mathrm{kg}$ ). The rat was perfused transcardially with about $200 \mathrm{ml}$ of a physiological saline solution followed by $500-800 \mathrm{ml}$ of $10 \%(\mathrm{v} / \mathrm{v})$ formalin in $0.1 \mathrm{M}$ phosphate buffer ( $\mathrm{pH} 7.3)$. Immediately after perfusion, the medial and lateral bulbocavernosus (ventral bulbospongiosus) muscles were excised from both sides, and their wet weights were measured. When the soleus muscle had been transplanted, the grafted soleus muscle and the contralateral, normal soleus muscle were similarly weighed. The spinal cord from the fourth lumbar through the first sacral segments was then removed. The spinal cord was stored in the same buffer containing $10 \%$ formalin for 4-5 d and in that containing $25 \%$ sucrose for 1 week at $4^{\circ} \mathrm{C}$. The spinal cord was cut serially into transverse sections of $50 \mu \mathrm{m}$ thickness on a freezing microtome. The sections were mounted in order on gelatinized slides and stained with $0.2 \%$ cresyl violet. As described previously (Breedlove and Arnold, 1981), identification of SNB neurons was based on their distinct location in the fifth and sixth lumbar segments (see Fig. 3). Only those SNB neurons with a clear nucleus contour were included in the study. The SNB neurons in every section were traced using a camera lucida drawing tube, and their cross-sectional areas were measured by a digitizing tablet attached to a computer.

The size of SNB neurons was measured 10 weeks after the following four different operative proccdurcs: (1) unilateral, chronic section of the pudendal nerve branch (see Fig. 4), (2) union of the cut pudendal nerve branch to the grafted soleus muscle on one side and reunion of the cut pudendal nerve branch to its peripheral stump (self-union) on the contralateral side without testosterone manipulation, (3) operative procedure (2) but combined with castration (see Fig. 6), or (4) operative procedure (3) but combined with testosterone treatment after castration (see Fig. 7). Four animals were used for each of these procedures. Castration and/or chronic testosterone treatment were applied on the day of the operation for peripheral nerves. In addition, the size of SNB neurons was measured in three rats 10 weeks after unilateral, chronic section of the pudendal nerve branch combined with union of the cut pudendal nerve branch to the grafted soleus muscle on the contralateral side (see Fig. 5).

In different experimental groups, the mean neuronal cross-sectional area of SNB neurons was calculated for each side in every animal, and the group means (the average of the mean neuronal sizes observed in individual animals for each group) were compared, using the number of animals per group as $n$. The statistical analysis was made by twotailed $t$ tests with a significance limit of $p<0.05$. When the mean sizes were compared between the SNB neurons that had reinnervated the perineal muscles and those that had innervated the grafted soleus muscle under different testosterone manipulations (see Fig. 8), a two-way analysis of variance (ANOVA) was employed. Similarly, an ANOVA was applied to comparison of the mean muscle weights under different tes- tosterone manipulations (see Fig. 2). All values are presented in the text as the mean and its standard deviation. Additional details of the experimental procedures are given in the appropriate sections of Results.

\section{Results}

\section{Changes of perineal muscles induced by denervation or} castration

The principal question posed in this study concerns hormonal regulation of the size of SNB neurons. However, the perineal muscles innervated by SNB neurons are also under the influence of the hormone. Therefore, changes in perineal muscles induced by denervation, castration, or testosterone treatment were initially examined. For this purpose, the wet weight of the medial and lateral bulbocavernosus (MLB) muscles was measured. Figure 1 shows changes in the mean MLB muscle weight on the denervated (solid circles) and contralateral, intact (open circles) sides $1-10$ weeks after unilateral section of the pudendal nerve (number of rats examined in each postoperative period, 4-8). At the time of the operation, all the animals were $180-200 \mathrm{gm}$ in body weight (see Materials and Methods). The mean body weight increased to $480 \mathrm{gm}$ during the 10 weeks after the operation. A progressive increase in the MLB muscle weight on the control side (Fig. 1, open circles) may be attributed to the growth of the animal during the postoperative period. In fact, the MLB muscle weight measured in normal rats whose body weights ranged from about 200 to $500 \mathrm{gm}$ was found to be almost linearly related to the body weight. In agreement with previous observations (Kare et al., 1955; Buresova et al., 1972; Godinho et al., 1987), the weight of the perineal muscles on the denervated side decreased with time after nerve section (Fig. 1, solid circles). These changes are essentially similar to denervation atrophy observed for skeletal muscle (Guth, 1968).

A similar comparison was made between the control and denervated sides in the animals in which castration had been made in combination with unilateral section of the pudendal nerve (number of animals examined in each postoperative period, 4-6). As shown by open triangles in Figure 1, castration resulted in atrophy of the MLB muscles on the control (innervated) side (Kare et al., 1955; Buresova et al., 1972; Godinho et al., 1987). This atrophy was significantly greater than that induced by denervation alone without castration (solid circles) in postoperative periods of more than 2 weeks. Furthermore, in castrated animals, the mean MLB muscle weights on the denervated side (Fig. 1, solid triangles) were consistently lower than those on the control side (open triangles). These differences were significant 4 and 10 weeks after the operation. Thus, the effects of castration and those of denervation on the MLB muscle weight were partly additive (see below).

In female rats, the perineal muscle undergoes postnatal involution (Cihak et al., 1970), and this process can be prevented by treatment with testosterone at birth even after denervation of the muscle (Buresova et al., 1972; Fishman and Breedlove, 1985). In adult male rats, however, testosterone has been reported to be no longer effective in increasing the weight of perineal muscles after denervation (Kare et al., 1955; Buresova et al., 1972). We reinvestigated this apparent paradox. Figure 2, $\mathrm{DB}$, shows the mean MLB muscle weights observed in three groups of animals in which the muscles had been denervated for 10 weeks. When castration had been combined with denervation, the mean denervated MLB muscle weight (Fig. 2B, DB) decreased to about $19 \%$ of that in untreated animals. When 


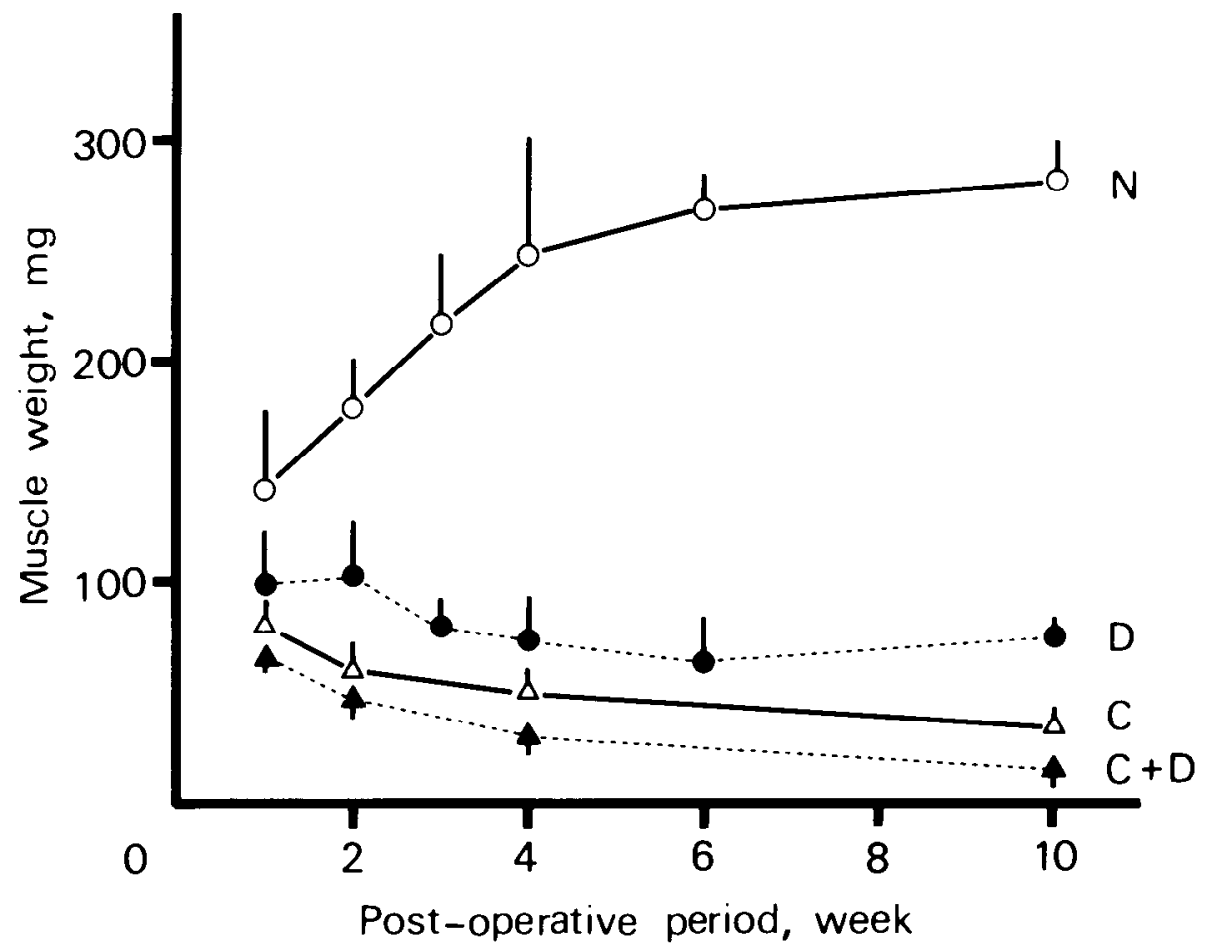

Figure 1. Changes in wet weight of the MLB muscles following unilateral transection of the pudendal nerve. Circles, the mean muscle weights on the innervated side $(N)$ and on the contralateral, denervated side $(D)$. Triangles, the mean muscle weights measured in castrated rats on the innervated side $(C)$ and on the contralateral, denervated side $(C+$ $D)$. Each point represents the mean \pm $\mathrm{SD}$ (vertical bar) from four to eight rats. castrated rats had been treated with testosterone, the mean denervated MLB muscle weight showed a 7.5-fold increase (Fig. $2 C, \mathrm{DB}$ ), compared with that in castrated animals (Fig. $2 B, \mathrm{DB}$ ). Therefore, there was little doubt that the denervated MLB muscles are still responsive to testosterone.

Open columns (RB) in Figure 2 show the mean weights of the MLB muscles whose nerves had been sectioned but immediately reunited to allow reinnervation of the perineal muscles 10 weeks previously. The mean weight of the reinnervated MLB muscles in untreated animals (Fig. $2 A$, RB) was about $85 \%$ of that in normal rats, but this difference was not statistically significant $(0.10<p<0.20)$. In castrated animals, the mean weight of the reinnervated MLB muscles decreased to about $14 \%$ of that in untreated rats (Fig. $2 B, \mathrm{RB}$ ), and this value showed a 6.7-fold increase when the castrated animals had been treated with testosterone (Fig. $2 C, \mathrm{RB}$ ). Thus, the rate of dec- rement or increment in muscle weight by testosterone manipulation was comparable in both the denervated and reinnervated MLB muscles, although these changes in the absolute value were less conspicuous in denervated muscles because of additional atrophy. This suggests that the regressive changes in the MLB muscles induced by denervation and those produced by castration may be based on independent mechanisms.

When a two-way ANOVA was applied to the wet weights of the denervated versus reinnervated $\mathrm{MLB}$ muscles under the three testosterone manipulations (Fig. 2, DB and RB), the factor related to the muscle and the factor related to hormone treatment were significantly $(p<0.01)$ different, as expected from the above $t$ tests. However, the presence of interactions between the two factors was also significant $(p<0.01)$. This implies that sensitivities of the denervated and reinnervated MLB muscles to the hormone are not identical.

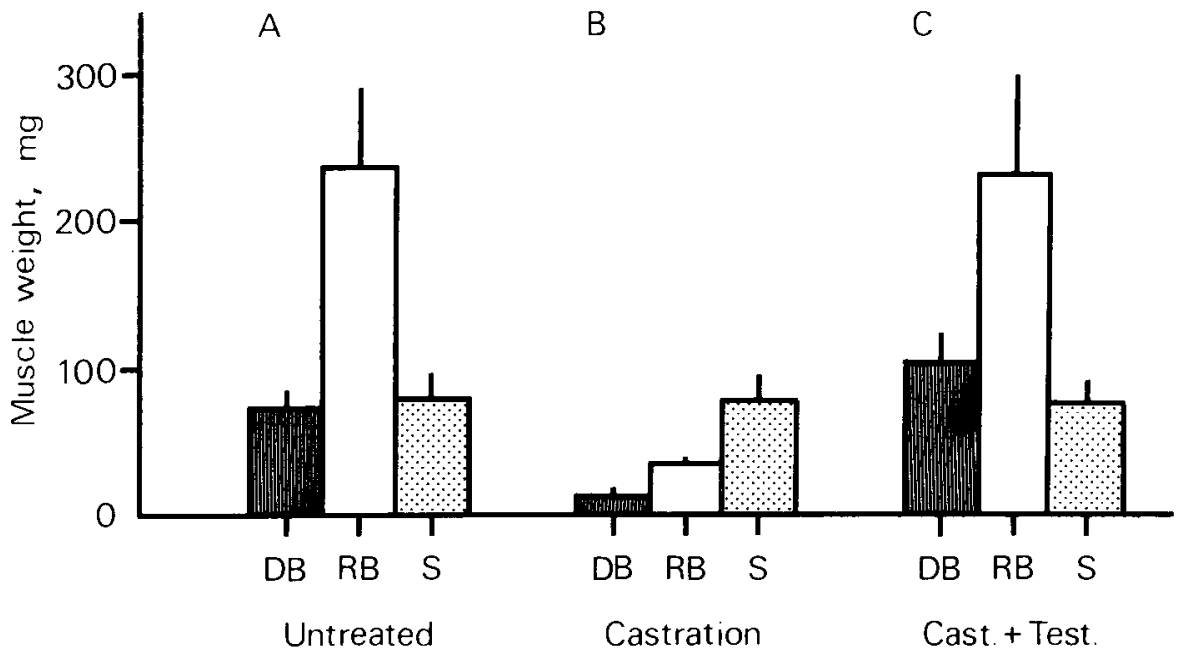

Untreated
Castration
Cast + Test
Figure 2. Effects of testosterone manipulation on the wet weight of the perineal and soleus muscles. $D B$, the MLB muscles denervated for 10 weeks. $R B$, the MLB muscles reunited by the cut pudendal nerve 10 weeks previously. $S$, the grafted solcus muscle unitcd by the cut pudendal nerve 10 weeks previously. During 10 weeks, the animals had been untreated $(A)$, castrated $(B)$, or treated with testosterone after castration $(C)$. Each column represents the mean $\pm \mathrm{SD}$ (vertical bar) from four to eight rats. 
Figure 3. Photomicrographs of SNB motoneurons that are clustered on each side in a region $150-400 \mu \mathrm{m}$ ventral to the central canal (top center in $A-D$ ) and within $250 \mu \mathrm{m}$ from the midline. $A$, SNB neurons on the normal $(n)$ and axotomized $(d)$ sides 10 weeks after unilateral section of the pudendal nerve. $B$, Ten weeks after reunion of the cut pudendal nerve to the grafted soleus muscle on one side $(s)$ and chronic section of the pudendal nerve on the contralateral side (d). $C$, Ten weeks after castration of a rat in which the cut pudendal nerve had been united to the grafted soleus muscle on one side $(s)$, whereas the contralateral pudendal nerve was cut and allowed to reinnervate the perineal muscles $(r) . D$, Similar to $C$, but the animal had been treated with testosterone after castration.
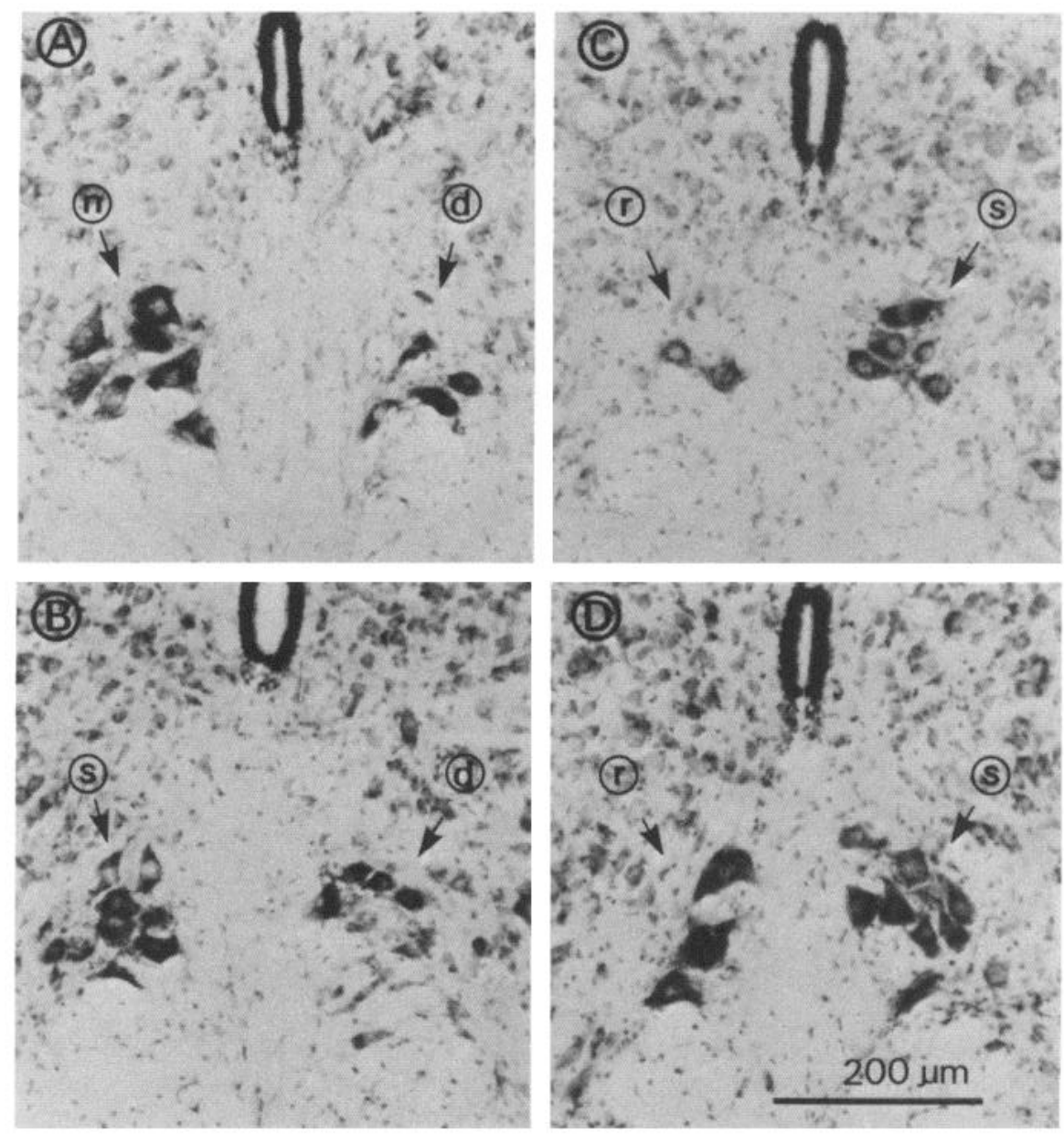

\section{The behavior of the soleus muscle reinnervated by SNB neurons}

Figure 2, S, shows the mean weights of the grafted soleus muscles reinnervated by SNB neurons in a postoperative period of 10 weeks, during which the animals had been exposed to different testosterone manipulations. The mean weight of the soleus muscles observed in five untreated rats (Fig. $2 A ; 80 \pm 17 \mathrm{mg} ; n=$ 5) was not affected by castration $(B ; 78 \pm 20 \mathrm{mg} ; n=7)$ or by testosterone treatment after castration $(C ; 78 \pm 10 \mathrm{mg} ; n=6)$ for 10 weeks. A two-way ANOVA showed that the factor related to the reinnervated MLB (Fig. 2, RB) versus grafted soleus muscles and the factor related to hormone treatment were significantly $(p<0.01)$ different. Also, the presence of interactions between the two factors was significant $(p<0.01)$. In this case, it is almost certain that this difference (interaction) is due to a lack of androgen sensitivity in the grafted soleus muscle. These results complement previous observations by Hanzlikova and Gutmann (1974; see Discussion).

\section{Changes in SNB neurons by axotomy}

Figure $3 A$ shows SNB neurons on the control $(n)$ and operated (d) sides 10 weeks after unilateral section of the pudendal nerve branch. The size of SNB neurons was generally smaller on the axotomized side than on the control side. Figure 4 (open histograms) shows the distribution of cross-sectional areas of SNB neurons for the control $(A)$ and axotomized $(B)$ sides. In this particular experiment, the mean cross-sectional area of SNB neurons on the control side was $1176 \mu \mathrm{m}^{2}$, whereas that on the axotomized side was $710 \mu \mathrm{m}^{2}$ (Fig. 4, arrowheads). Similar observations were made on four rats. The mean cross-sectional area of SNB neurons varied considerably from one animal to another on both the control and axotomized sides. However, the average of the mean values on the axotomized side in the four animals $\left(827 \pm 207 \mu \mathrm{m}^{2} ; n=4\right)$ was significantly ( $p<$ $0.05)$ smaller than that on the control side $\left(1368 \pm 194 \mu \mathrm{m}^{2}\right.$; $n=4)$.

The number of SNB neurons was consistently fewer on the axotomized side in the four rats. In one rat, SNB neurons on the axotomized side (105) were exceptionally fewer than those counted on the control side (156). Including this animal, the mean raw count of SNB neurons on the axotomized side (134 $\pm 23 ; n=4)$ was significantly $(p<0.05)$ lower than that on the control side $(172 \pm 14 ; n=4)$. We measured the areas of neuronal nuclei in 33-59 SNB neurons sampled from both sides of every animal. The average of the mean nucleal areas on the axotomized side (186 $\left.\pm 55 \mu \mathrm{m}^{2} ; n=4\right)$ was significantly $(p<$ $0.05)$ smaller than that on the control side $\left(281 \pm 43 \mu \mathrm{m}^{2} ; n=\right.$ 4). Similarly, the average diameter of nuclei calculated from the nucleal area was significantly $(p<0.05)$ smaller on the axotomized side $(15.3 \pm 2.3 \mu \mathrm{m} ; n=4)$ than that on the control side $(18.9 \pm 1.5 \mu \mathrm{m} ; n=4)$. Therefore, the chance of each neuronal nucleus being split in a section would be greater for SNB neurons on the control side than for axotomized SNB neurons, and hence, an overestimation of the neuronal number would be greater in the former than in the latter. Thus, the possibility of 


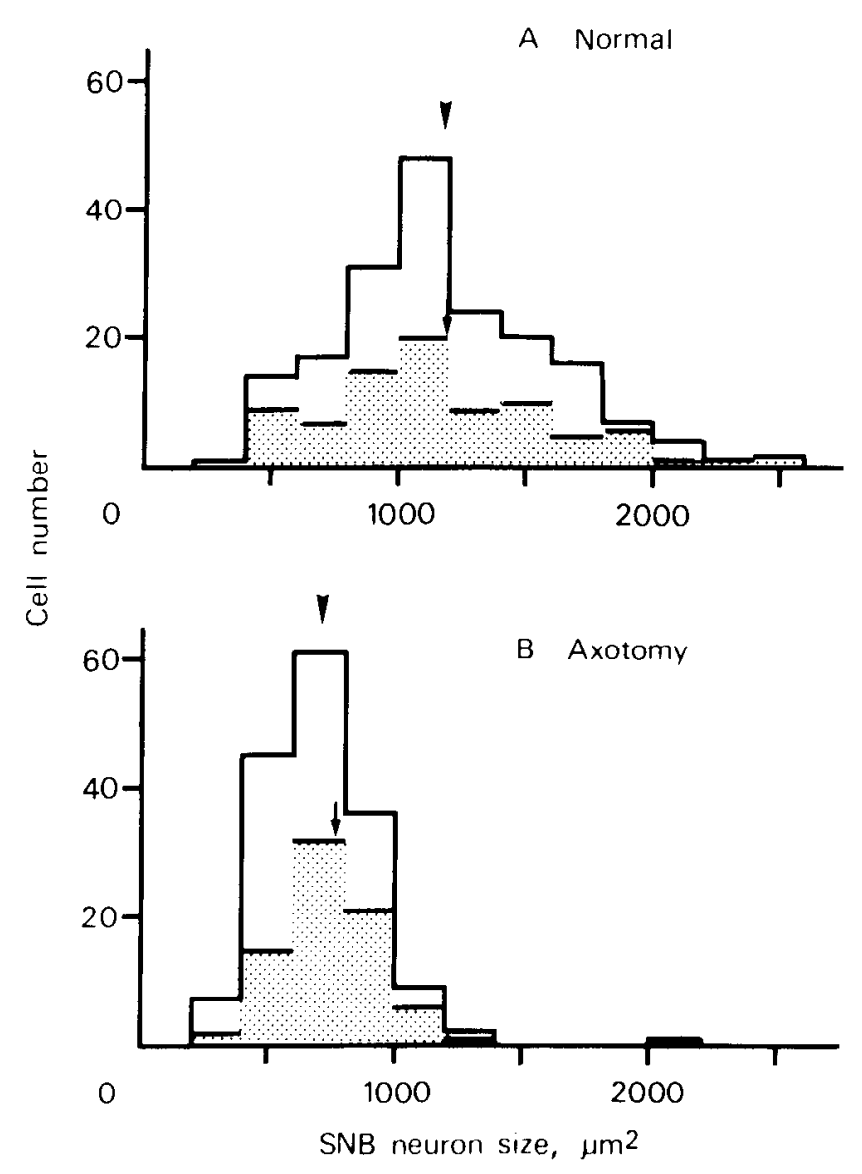

Figure 4. Distributions of cross-sectional areas of individual SNB neurons measured in a rat 10 weeks after unilateral section of the pudendal nerve. $A$, SNB neurons on the normally innervated side. $B$, SNB neurons on the contralateral side, in which the pudendal nerve had been cut repeatedly every 2 weeks. Open histograms, the results obtained by measurements of SNB neurons seen in all sections, which might include double measurement of the same neuron spanning two neighboring sections. Arrowheads, mean values. Shaded histograms, the results obtained by measurements of SNB neurons sampled from every other section. Arrows, mean values.

double counting of the same SNB neuron was corrected for by the method of Abercrombie (1946), using the mean nucleal diameter measured for each side of every animal. With this correction, the mean number of SNB neurons on the axotomized side $(105 \pm 16 ; n=4)$ was not significantly different $(0.05<p$ $<0.10)$ from that on the control side $(125 \pm 8 ; n=4)$. However, the mean ratio of the corrected numbers of SNB neurons between the axotomized and control sides $(0.88 \pm 0.05 ; n=4)$ was significantly $(p<0.05)$ different from unity. Thus, cell death might be induced in about $10 \%$ of SNB neurons during 10 weeks after axotomy.

From the above correction, it is likely that the open histograms in Figure 4 may include some SNB neurons (about 25\%) that might span two neighboring sections and might be measured twice. In order to avoid this complication due to double measurement, we evaluated the neuron size measured in every other section. Since the scction thickness is $50 \mu \mathrm{m}$ and the mean nucleal diameter is about $20 \mu \mathrm{m}$, there will be no possibility that a given neuron may be measured twice under this condition. The size distributions measured in this manner are illustrated by shaded histograms in Figure 4 . The mean cross-sectional area of SNB neurons measured on the axotomized side (850 \pm

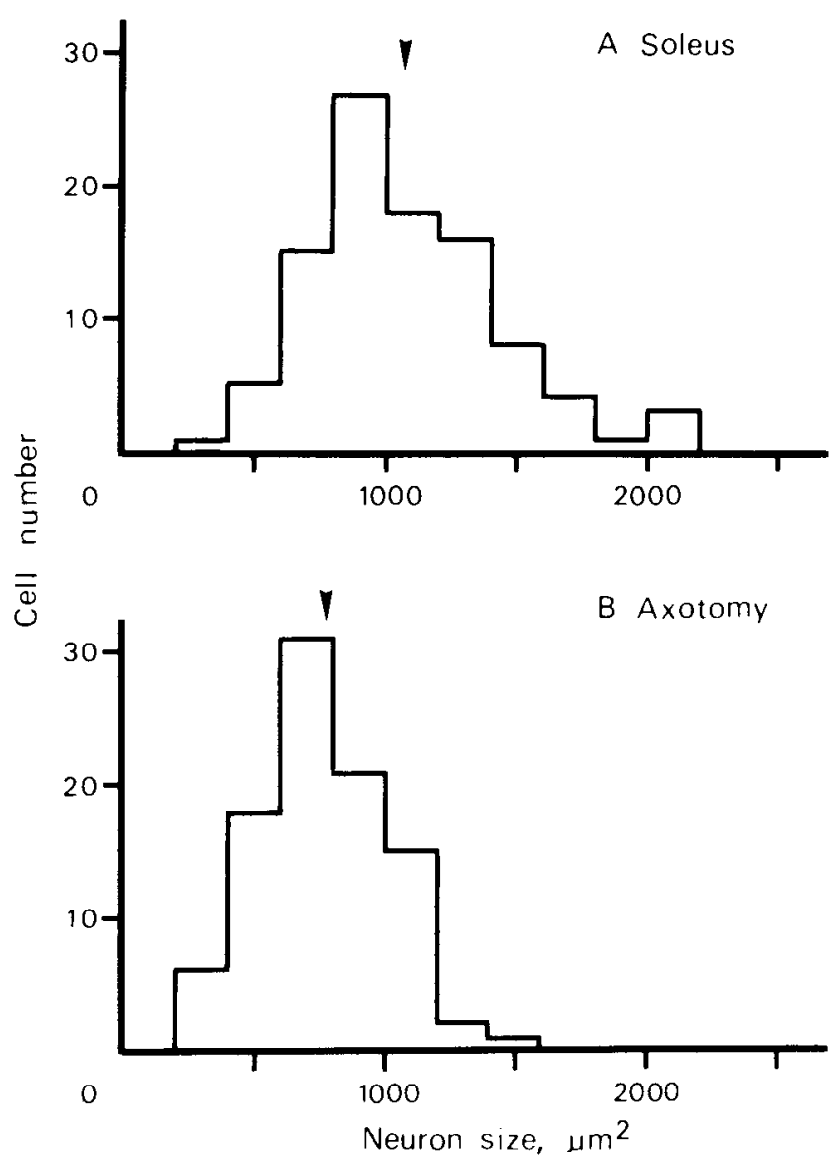

Figure 5. Distributions of cross-sectional areas of individual SNB neurons measured in a rat in which the cut pudendal nerve had been reunited to the soleus muscle on one side, whereas the contralateral pudendal nerve had been cut repeatedly every 2 weeks. Measurements were made 10 weeks after the operation. $A$, SNB neurons innervating the soleus muscle. $B$, SNB neurons axotomized on the contralateral side. Arrowheads, mean values. The results are based on measurements of SNB neurons sampled from every other section.

$\left.231 \mu \mathrm{m}^{2} ; n=4\right)$ was again significantly $(p<0.05)$ smaller than that on the control side $\left(1353 \pm 183 \mu \mathrm{m}^{2} ; n=4\right)$.

The mean neuronal size evaluated by measuring the area of SNB neurons seen in all sections did not differ by more than a few percent from that evaluated by the area of the neurons measured in every other section. Since the effect of double measurement is unpredictable under different testosterone manipulations, the neuron size was evaluated by measurements made in every other section for all the experiments described below.

\section{The size of $S N B$ neurons reinnervating the perineal or soleus} muscle

In four rats, the pudendal nerve branch was cut and immediately reunited to allow reinnervation of the perineal muscles. The mean cross-sectional area of SNB neurons measured in every other section 10 weeks later in these animals was $1243 \pm 137$ $\mu \mathrm{m}^{2}$ ( $n=4$; see Fig. 8, Untreated, C). This was significantly ( $p$ $<0.05$ ) greater than the mean value of axotomized SNB neurons but not significantly $(0.40<p<0.30)$ different from that of normal SNB neurons. Thus, a reduction in size of SNB neurons induced by removal of their targets appears to be restored following their peripheral reinnervation.

It might be asked whether the size of SNB neurons can be maintained even by cross-union of their peripheral nerve to a 


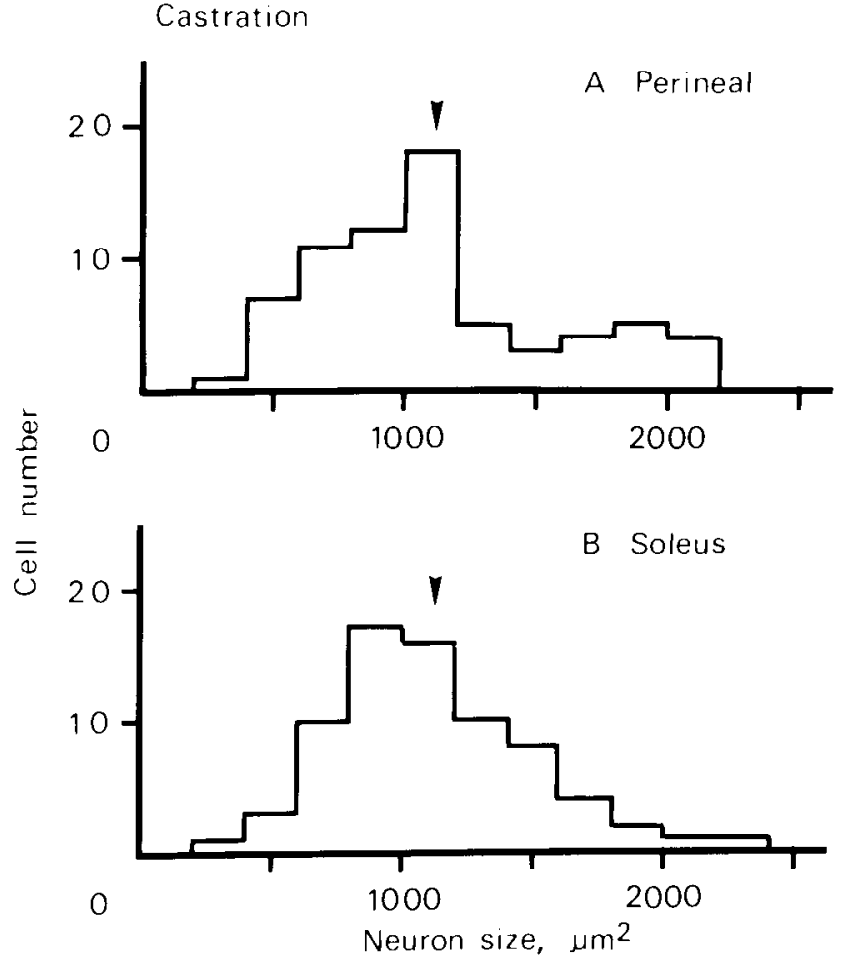

Figure 6. Distributions of cross-sectional areas of individual SNB neurons measured in a rat in which the pudendal nerve had been cut and allowed to reinnervate the original perineal muscles on one side, whereas the contralateral pudendal nerve had been cut and united to the grafted soleus muscle. The animal was castrated on the day of the opcration for peripheral nerves and killed 10 weeks later. $A$, SNB neurons reinnervating the perineal muscles. $B$, SNB neurons innervating the grafted soleus muscle. Arrowheads, mean values. The results are based on measurements of SNB neurons sampled from every other section.

foreign skeletal muscle. To address this question, the pudendal nerve branch was cut and united to the grafted soleus muscle on one side, whereas the pudendal nerve branch on the contralateral side was repeatedly sectioned every 2 weeks. Figure $3 B$ shows a specimen of SNB neurons prepared 10 weeks after this operation. The size distributions of SNB neurons on the side united to the soleus muscle $(A)$ and on the chronically axotomized side $(B)$ are exemplified in Figure 5 . The averages of the mean sizes of SNB neurons measured in every other section on both sides were compared in three rats. The average size of SNB neurons that had innervated the soleus muscle $(1081 \pm 84 \mu \mathrm{m}$; $n=3$ ) was significantly ( $p<0.005$ ) larger than that of chronically axotomized SNB neurons on the contralateral side $(728 \pm 40$ $\mu \mathrm{m}^{2}$ ). Furthermore, the mean sizes of SNB neurons were compared in four rats in which SNB neurons on one side had reinnervated the perineal muscles (1243 $\mu \mathrm{m}^{2}$; see above), whereas those on the contralateral side had innervated the grafted soleus muscle (1051 $\pm 109 \mu \mathrm{m}^{2} ; n=4$; see Fig. 8, Untreated, $\left.S\right)$. There was a tendency for the SNB neurons innervating the soleus muscle to be smaller than those reinnervating the perineal muscles. However, the statistical significance of this difference was marginal $(0.05<p<0.10)$. Thus, the size of SNB neurons appears to be maintained almost equally well by the foreign skeletal muscle, compared with their own target muscles.

\section{The behavior of SNB neurons that innervate the soleus muscle} Is the size of SNB neurons innervating the soleus muscle affected by testosterone manipulation? Figure $3 C$ shows an example of

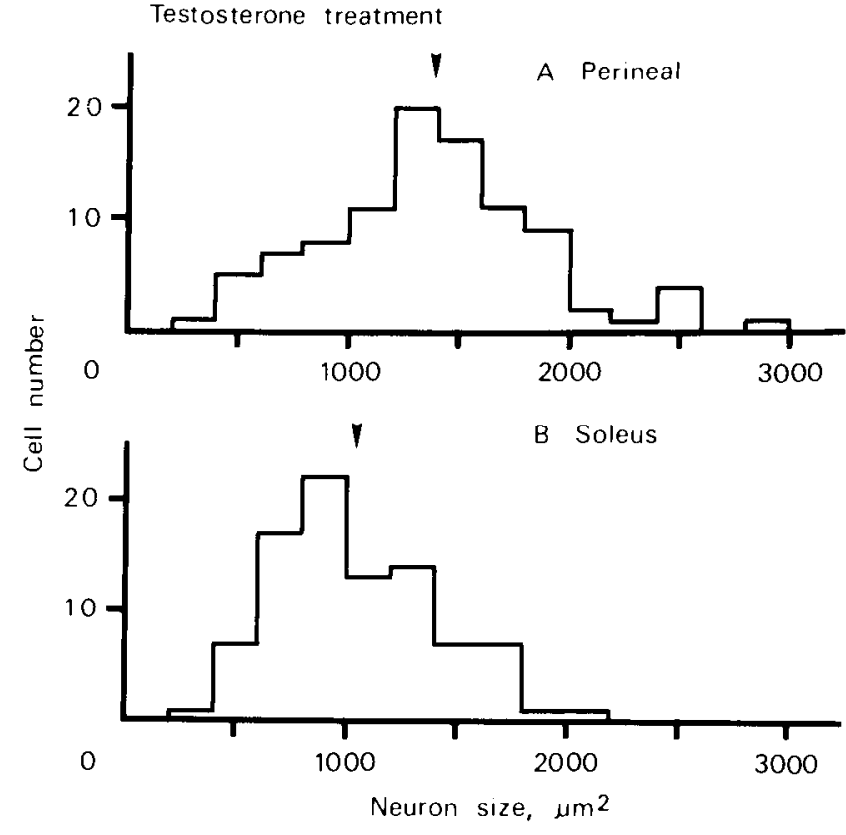

Figure 7. Distributions of cross-sectional areas of individual SNB neurons on both sides in a rat. The procedure of the operation for the pudendal nerves was the same as in Figure 6, but the animal had been treated with testosterone after castration for 10 weeks. $A$, SNB neurons reinnervating the perineal muscles. $B$, SNB neurons innervating the grafted soleus muscle. Arrowheads, mean values. The results were based on measurements of SNB neurons sampled from every other section.

SNB neurons that had reinnervated the perineal muscles on one side (r) and innervated the grafted soleus muscle on the contralateral side (s) during 10 weeks after castration. An example shown in Figure $3 D$ was obtained from the animal that had been subjected to a similar operation but treated with testosterone after castration for 10 weeks. The distributions of cross-sectional areas of SNB neurons reinnervating the perineal muscles $(A)$ and innervating the grafted soleus muscle $(B)$, are illustrated in Figures 6 and 7, respectively, for a castrated animal and an animal treated with testosterone after castration. These results show that treatment of the castrated animal with testosterone increases the size of SNB neurons reinnervating the perineal muscles, whereas the size of SNB neurons innervating the grafted soleus muscle is not affected by the hormonal treatment.

Figure 8 summarizes changes in the mean sizes of SNB neurons reinnervating the perincal muscles $(C)$ and of those innervating the soleus muscle (S) in response to testosterone manipulation. The size of SNB neurons reinnervating the perineal muscles was significantly $(p<0.05)$ reduced by castration $(1000$ $\left.\pm 92 \mu \mathrm{m}^{2} ; n=4\right)$, and this effect was significantly $(p<0.001)$ prevented by testosterone treatment after castration (1371 \pm $\left.36 \mu \mathrm{m}^{2} ; n=4\right)$. In contrast, the size of SNB neurons innervating the soleus muscle was affected neither by castration (1028 \pm $\left.142 \mu \mathrm{m}^{2} ; n=4\right)$ nor by testosterone treatment (1087 $\pm 65 \mu \mathrm{m}^{2}$; $n=4)$. As mentioned above, the difference in size between the SNB neurons reinnervating the perineal muscles and those innervating the soleus muscle in untreated animals was statistically marginal. However, this difference in the animals treated with testosterone was highly significant $(p<0.005)$. Furthermore, a two-way ANOVA showed that the factor related to these SNB neurons and the factor related to testosterone manipulation were significantly $(p<0.01)$ different. Also, the presence of interactions between the two factors was significant ( $p$ 


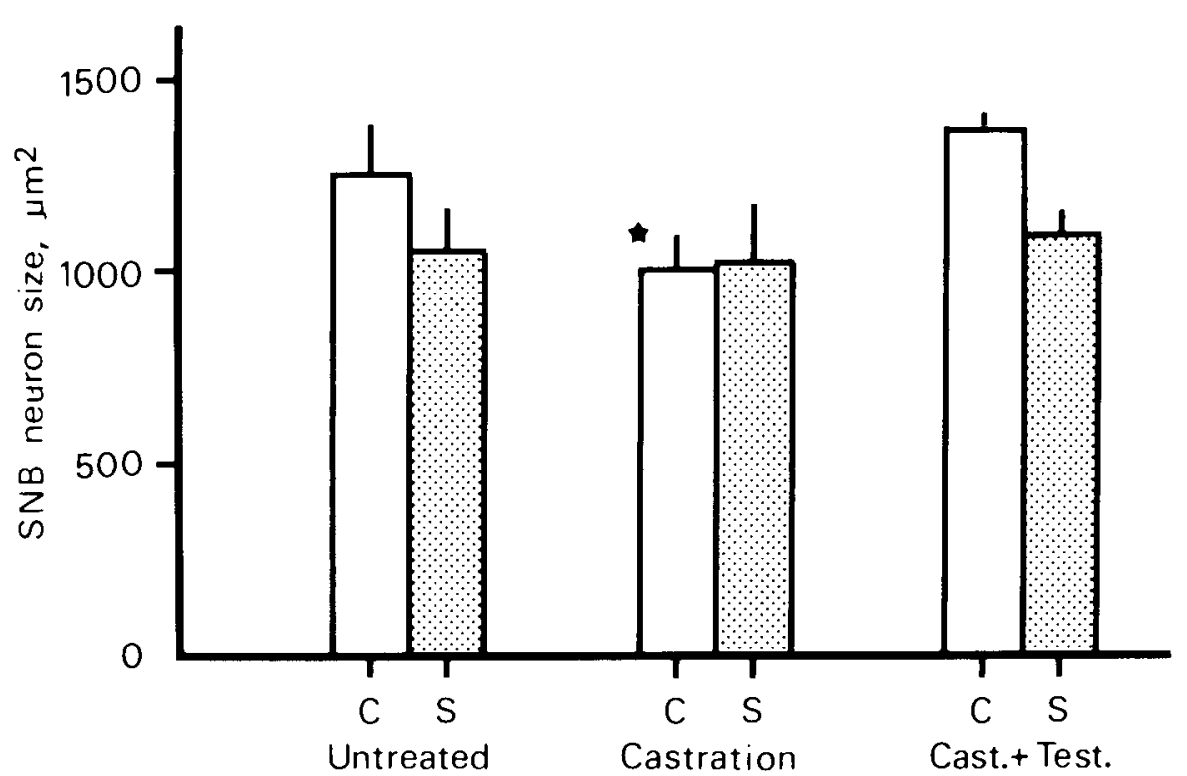

Figure 8. Comparison of the mean cross-sectional areas between SNB neurons reinnervating the perineal muscles $(C)$ and those innervating the grafted soleus muscle $(S)$ in three groups of animals. The three groups of animals had been untreated, castrated, or treated with testosterone after castration for 10 weeks. Each column represents the mean $\pm \mathrm{SD}$ (vertical bar) from four rats. $A s$ terisk, significant difference from the value of the untreated animals or testosterone treated animals. The results are based on measurements of SNB neurons sampled from every other section.
$<0.05)$. Thus, alterations in the size of SNB neurons in response to testosterone manipulation appear to depend upon the presence or absence of androgen sensitivity in the reinnervated muscle. Therefore, it is concluded that hormonal regulation of the size of SNB neurons is mediated by their target muscles.

\section{Discussion}

The present results confirmed previous observations that the weight of the bulbocavernosus muscle in adult male rats is markedly reduced following castration and increased by treatment with testosterone (Wainman and Shipounoff, 1941; Eisenberg and Gordan, 1950; Venable, 1966). These changes induced by testosterone manipulation were observed even in chronically denervated bulbocavernosus muscles, although androgen sensitivity might not be identical in the innervated and denervated muscles. Therefore, testosterone must act directly on the perineal muscles. This is consistent with the finding that the perineal muscle cross-reinnervated by a branch of the sciatic nerve still shows atrophy in response to castration and hypertrophy by treatment with testosterone (Hanzlikova and Gutmann, 1972). Conversely, the wet weight of the soleus muscle reinnervated by SNB motoneurons was unaffected by castration or by treatment with testosterone, as reported previously (Hanzlikova and Gutmann, 1974). Thus, the hormone sensitivity of perineal muscles is of myogenic origin.

The present study showed that changes in the size of SNB neurons in response to testosterone manipulation occurred only when the neurons had reinnervated the hormone-sensitive perineal muscles, but not when they had reinnervated the hormoneinsensitive soleus muscle. If a direct action of androgen on SNB neurons were involved in regulation of their size, the size of SNB neurons innervating the grafted soleus muscle would be expected to be enlarged by testosterone treatment, compared with that following castration alone. Since this was not the case (Fig. 8), it seems reasonable to conclude that hormonal regulation of the size of SNB motoneurons is executed mainly, if not entirely, via their target muscles.

Virtually all of SNB neurons are known to accumulate testosterone when the labeled hormone is systemically applied to adult rats (Breedlove and Arnold, 1980, 1983). The functional significance of this phenomenon is not clear. It has been reported that the SNB neurons innervating a sexually nondimorphic anal sphincter in female rats are enlarged in response to testosterone applied in postnatal days $7-11$, but not after this period (Lee et al., 1989). It is possible that SNB neurons may respond directly to androgen at early postnatal stages. The motoneurons innervating the anal sphincter muscle comprise about $30 \%$ of the neurons in the SNB. These neurons are preserved in adult female rats as well as in adult male rats, and their sizes are not different in both sexes (McKenna and Nadelhaft, 1986). Thus, the size of the SNB neurons innervating the anal sphincter may be unaffected by testosterone manipulation, although SNB neurons in adult female rats can be enlarged by daily injections of relatively large doses of androgen (Breedlove and Arnold, 1981). When the cut pudendal nerve branch had been reunited to its peripheral stump, the SNB neurons might not selectively reinnervate their original target muscles. The SNB neurons originally innervating the sexually dimorphic muscles (levator ani and bulbocavernosus) might reinnervate the anal sphincter. Similarly, the SNB neurons originally innervating the anal sphincter might reinnervate the sexually dimorphic muscles. It is not known how these "misrouted" SNB neurons responded to testosterone manipulation. The SNB neurons that responded to testosterone manipulation after reinnervation of the perineal muscles might be those that had reinnervated the sexually dimorphic muscles, irrespective of the original target muscles or, alternatively, those that had originally innervated the sexually dimorphic muscles, irrespective of the reinnervated target muscles. The present results with the grafted soleus muscle suggest that the former is the case. However, this prediction remains to be evaluated.

The dendritic fields of rat hypoglossal motoneurons are known to be retracted by loss of their peripheral functional neuromuscular transmission and expanded again following restoration of the junctional transmission (Sumner and Watson, 1971). Similarly, the dendritic length of individual sympathetic neurons is reduced after axotomy and increases in parallel with reinnervation of their peripheral targets (Yawo, 1987). Also, when the target size had been experimentally altered, the dendritic length of sympathetic ganglion cells was found to be correlated with the target size (Voyvodic, 1989). These results suggest that the 
neuronal size of sympathetic ganglion cells is regulated by interactions with their targets, presumably by the amount of the neurotrophic factor retrogradely supplied from the targets (Purves et al., 1988). In fact, a marked increase in the dendritic length of sympathetic neurons has been found following administration of NGF (Snider, 1988). By analogy, it may be assumed that the size of SNB neurons is also regulated by some as yet unidentified neurotrophic factor supplied from their target muscles. Furthermore, the synthesis of the trophic factor in the perineal muscles may be assumed to be enhanced by testosterone.

Following cross-union of the cut pudendal nerve branch to the grafted soleus muscle, its functional innervation was not examined in the present study. However, the presence of innervation of the soleus muscle by SNB neurons was supported for three reasons. First, after perfusion of the animal, insertion of the cut pudendal nerve branch in the soleus muscle was confirmed in cvery rat. Sccond, the mean wet weight of the grafted soleus muscle in a postoperative period of 10 weeks was about $70 \%$ of that of the contralateral, normal soleus muscle (see Materials and Methods), whereas the wet weight of the soleus muscle is known to decrease to $55 \%$ of the control value within 2 weeks after denervation (Godinho et al., 1987). Third, SNB neurons whose peripheral nerves had been united to the grafted soleus muscle were significantly larger than chronically axotomized SNB neurons (Fig. 5). Thus, it seems clear that the size of SNB neurons could be maintained by cross-union of their peripheral nerve to the soleus muscle. This suggests that the retrograde trophic factor supplied from perineal muscles to the SNB motoneurons may be homologous to the trophic factor originating from androgen-insensitive skeletal muscle. The electrophysiological properties of spinal motoneurons can be altered, depending upon mechanical activity of the innervated skelctal muscle (Czch ct al., 1979; Gallego ct al., 1979; Kuno, 1990). At present, it is not known whether trophic influence from perineal muscles may also be regulated by mechanical activity of the muscle, in addition to testosterone.

SNB motoneurons are considered to be the rat homologue of Onufs nucleus in man (Onuf, 1900; Schroder, 1985). Motoneurons in Onufs nucleus in man are also sexually dimorphic (Forger and Breedlove, 1986) and appear to innervate the striated external sphincter muscles of the anus and urethra (Mannen et al., 1982). In patients with motoneuron disease, motoneurons in Onuf's nucleus escape cell death (Mannen et al., 1977, 1982; Gibson et al., 1988). Appel (1981) has suggested that cell death in patients with motoneuron disease may result from diminished availability of a neurotrophic factor normally supplied from the target muscle. If this were the case, it would be possible that Onuf's nucleus may be preserved because of continual stimulation of the synthesis of the trophic factor by testostcronc in the blood.

\section{References}

Abercrombie M (1946) Estimation of nuclear population from microtome sections. Anat Rec 94:239-247.

Appel SH (1981) A unifying hypothesis for the cause of amyotrophic lateral sclerosis, parkinsonism, and Alzheimer disease. Ann Neurol 10:499-505.

Arnold AP (1984) Androgen regulation of motor neuron size and number. Trends Neurosci 7:239-242.

Breedlove SM (1986) Cellular analyses of hormone influence on motoneuronal development and function. J Neurobiol 17:157-176.

Breedlove SM, Amold AP (1980) Hormone accumulation in a sexually dimorphic motor nucleus of the rat spinal cord. Science 210:564 566.

Breedlove SM, Arnold AP (1981) Sexually dimorphic motor nucleus in rat spinal cord: response to adult hormone manipulation, absence in androgen-insensitive rats. Brain Res 225:297-307.

Breedlove SM, Arnold AP (1983) Sex differences in the pattern of steroid accumulation by motoneurons of the rat lumbar spinal cord. J Comp Neurol 215:211-216.

Buresova SM, Gutmann ME, Hanzlikova V (1972) Differential effects of castration and denervation on protein synthesis in the levator ani muscle of the rat. J Endocrinol 54:3-14.

Carlson BM, Hansen-Smith FM, Magon DK (1979) The life history of a free muscle graft. In: Muscle regeneration (Mauro A, ed), pp 493507. New York: Raven.

Cihak R, Gutmann E, Hanzlikova V (1970) Involution and hormoneinduced persistence of the $\mathrm{M}$. sphincter (levator) ani in female rats. J Anat 106:93-110.

Czeh G, Gallego R, Kudo N, Kuno M (1979) Evidence for the maintenance of motoneurone properties by muscle activity. J Physiol (Lond) 281:239-252.

Dube JY, Lesage R, Tremblay RR (1976) Androgen and estrogen binding in rat skeletal and perineal muscles. Can J Biochem 54:5055.

Eisenberg E, Gordan GS (1950) The levator ani muscle of the rat as an index of myotrophic activity. J Pharmacol Exp Ther 99:38-44.

Fishman RB, Breedlove SM (1985) Neonatal androgen maintains sexually dimorphic perineal muscles in the absence of innervation. Soc Neurosci Abstr 11:530.

Forger NG, Breedlove SM (1986) Sexual dimorphism in human and canine spinal cord: role of early androgen. Proc Natl Acad Sci USA 83:7527-7531.

Gallego RM, Kuno M, Nunez R, Snider WD (1979) Dependence of motoneurone properties on the length of immobilized muscle. J Physiol (Lond) 291:179-189.

Gibson SJ, Polak JM, Katagiri T, Su H, Weller RO, Brownell DB, Holland S, Hughes JT, Kikuyama S, Ball J, Bloom SR, Steiner TJ, De Belleroche J, Rose FC (1988) A comparison of the distribution of eight peptides in spinal cord from normal controls and cases of motor neuron disease with special reference to Onuf's nucleus. Brain Res 474:255-278.

Godinho RO, Lima-Landman MT, Souccar C, Lapa AJ (1987) Trophic control of cholinesterase activity in a testosterone-dependent musclc of the rat: effects of castration and dencrvation. Exp Neurol 96:558-568

Guth L (1968) 'Trophic' influences of nerve on muscle. Physiol Rev 48:645-687.

Hanzlikova V, Gutmann E (1972) Effect of foreign innervation on the androgen-sensitive levator ani muscle of the rat. Z Zellforsch 135: 165-174.

Hanzlikova V, Gutmann E (1974) The absence of androgen-sensitivity in the grafted soleus muscle innervated by the pudendal nerve. Cell Tissue Res 154:121-129.

Hironaka T, Miyata Y (1973) Transplantation of an entire muscle in mice. Experientia 29:1584-1586.

Jung I, Baulieu EE (1972) Testosterone cytosol "receptor" in the rat levator ani muscle. Nature 237:24-25.

Kare MR, Medway W, Brandt CS (1955) Effect of denervation on a hormone-sensitive muscle. Am J Physiol 183:416-418.

Kuno M (1990) Target dependence of motoneuronal survival: the current status. Neurosci Res 9:155-172.

Kurz E, Sengelaub DR, Arnold AP (1986) Androgens regulate the dendritic length of mammalian motoneurons in adulthood. Science 232:395-398.

Lee JH, Jordan CL, Arnold AP (1989) Critical period for androgenic regulation of soma size of sexually dimorphic motoneurons in rat lumbar spinal cord. Neurosci Lett 98:79-84.

Mannen T, Iwata M, Toyokura Y, Nagashima K (1977) Preservation of a certain motoneurone group of the sacral cord in amyotrophic lateral sclerosis: its clinical significance. J Neurol Neurosurg Psychiatry 40:464-469.

Mannen T, Iwata M, Toyokura Y, Nagahima K (1982) The Onuf's nucleus and the external anal sphincter muscles in amyotrophic lateral sclerosis and Shy-Drager syndrome. Acta Neuropathol (Berl) 58:255260. 
Matsumoto A, Micevych PE, Arnold AP (1988) Androgen regulates synaptic input to motoneurons of the adult rat spinal cord. J Neurosci 8:4168-4176.

McKenna K, Nadelhaft I (1986) The organization of the pudendal nerve in the male and female rat. J Comp Neurol 248:532-549.

Menniti FS, Baum MJ (1981) Differential effects of estrogen and androgen on locomotor activity induced by castrated male rats by amphetamine, a novel environment, or apomorphine. Brain Res 216: 89-107.

Nordeen EJ, Nordeen KW, Sengelaub DR, Arnold AP (1985) Androgens prevent normally occurring cell death in a sexually dimorphic spinal nucleus. Science 229:671-673.

Onuf (Onufrowicz) B (1900) On the arrangement and function of the cell groups of the sacral region of the spinal cord in man. Arch Neurol Psychopathol 3:387-412.

Purves D, Snider WD, Voyvodic JT (1988) Trophic regulation of nerve cell morphology and innervation in the autonomic nervous system. Nature 336:123-128.

Schroder HD (1980) Organization of the motoneurons innervating the pelvic muscles of the male rat. J Comp Neurol 192:567-587.

Schroder HD (1985) Anatomical and pathoanatomical studies on the spinal efferent systems innervating pelvic structures. J Autonom Nerv Syst 14:23-48.

Sengelaub DR, Arnold AP (1986) Development and loss of early projections in a sexually dimorphic rat spinal nucleus. J Neurosci 6: $1613-1620$

Sengelaub DR, Arnold AP (1989) Hormonal control of neuron number in sexually dimorphic spinal nuclei of the rat: I. Testosterone-regulated death in the dorsolateral nucleus. J Comp Neurol 280:622-629.

Sengelaub DR, Nordeen EJ, Nordeen KW, Arnold AP (1989) Hormonal control of neuron number in sexually dimorphic spinal nuclei of the rat: III. Differential effects of the androgen dihydrotestosterone. J Comp Neurol 280:637-644.

Snider WD (1988) Nerve growth factor enhances dendritic arborization of sympathetic ganglion cells in developing mammals. J Neurosci $8: 2628-2634$

Sumner BEH, Watson WE (1971) Retraction and expansion of the dendritic tree of motor neurones of adult rats induced in vivo. Nature 233:273-275.

Ueyama T, Arakawa H, Mizuno N (1987) Central distribution of efferent and afferent components of the pudendal nerve in rat. Anat Embryol 177:37-49.

Venable JH (1966) Morphology of the cells of normal, testosteronedeprived, and testosterone-stimulated levator ani muscles. Am J Anat 119:271-302.

Voyvodic JT (1989) Peripheral target regulation of dendritic geometry in the rat superior cervical ganglion. J Neurosci 9:1997-2010.

Wainman P, Shipounoff GC (1941) The effects of castration and testosterone proprionate on the striated perineal musculature of the rat. Endocrinology 29:975-978.

Yawo H (1987) Changes in the dendritic geometry of mouse superior cervical ganglion cells following postganglionic axotomy. J Neurosci 7:3703-3711. 